\title{
Los negocios de garantía
}

\section{Noemí Lidia Nicolau*}

"Rendir homenaje a Clóvis do Couto e Silva es evocar juntamente un modelo de hombre, maestro y jurista. Sus discípulos y quienes tuvimos la oportunidad de conocerlo sufrimos con sorpresa y dolor su temprana partida. Desde Argentina, vaya mi recuerdo emocionado para quien fue capaz de establecer profundos lazos de amistad e intercambio intelectual entre la Universidad de Porto Alegre y las universidades de mipaís.

Profesor Clóvis fue un maestro abnegado y un jurista brillante que umarchó siempre por el camino que conduce a lo alto, practicando en toda forma la justicia con ayuda de la inteligencias (Platón, República, 621)".

1. Tanto desde el punto de vista jurídico como desde el económico, no cabe duda de que, por estar vinculados directamente al crédito, los negocios de garantía son altamente significativos.

Desde lo jurídico tratar las garantías significa introducirse en el campo de la tutela del crédito ${ }^{1}$, que es una especie dentro del vasto tema de la tutela de los derechos. Ese es el esquema metodológico del Código civil italiano que reúne las acciones de garantía en su último libro bajo el título "Tutela de los derechos"”.

\footnotetext{
"Investigadora del Consejo de Investigaciones de la Universidad Nacional de Rosario. Este trabajo sintetiza las reflexiones expuestas en la apertura del Seminario "Negocios juríoicos de garantía", realizado durante los días 1 y 2 de agosto de 1997 y organizado por el centro de Investigaciones de Derecho civl, Faculdad te Derecho, Universidad Nacional de Ro ario y en la Carrera de posgrado de Derecho empresarial, Secretaría de postgrado y servicio a terceros, Facultad de Ciencias Jurídicas y Sociales, Universidad Nacional del Litoral.

1 Para un estudio panorámico del crédito desde el punto de vista jurídico no puede dejar de consultarse un clásico en la materia como es $\mathrm{KOCH}$, Arwed, El crédito en el derecho, trad. José M.Navas, ERDP, Madrid, 1946.

${ }^{2}$ El libro sexto incluye, junto a la publicidad registral, prueba, privilegios, acciones conservatorias, prescripción, prenda e hipoteca. Omite la fianza que es tratada en el libro cuarto "De las obligaciones".
} 
Cuando el ordenamiento normativo los regula de manera adecuada ${ }^{3}$ los negocios de garantía coadyuvan a la seguridad jurídica y al desarrollo económico. A causa de su estrecha relación con la economía, cualquier cambio en esta área incide directamente en la jurídica. Así, en momentos de depresión económica, al disminuir el crédito disminuye el otorgamiento de garantías, mientras que, en épocas de bonanza se acrecienta su número, en especial, con relación a las que ofrecen mayores seguridades a largo plazo.

A su vez, el régimen de garantías puede influir positiva o negativamente en la economía global. De modo positivo, facilitando la concesión de créditos y su recupero por los acreedores, y de modo negativo, distorsionando el mercado al facilitar la concesión indiscriminada de crédito. En efecto, si el régimen de garantías es eficiente y asegura el recupero, puede llevar indirectamente a los acreedores, especialmente financieros, a conceder créditos fáciles y con escasos límites, llegando en ocasiones a crear una verdadera apariencia de solvencia, todo lo cual, a la postre resulta nocivo para la economía general e, incluso, puede hacer incurrir a los mismos en responsabilidad civil frente a terceros ${ }^{4}$.

En síntesis, estos negocios facilitan al deudor el acceso al crédito, y al acreedor, una rápida satisfacción del mismo. Pero para ello deben ser ágiles, es decir, en términos jurídicos, deben gozar de libertad de formas y ser poco onerosos, no sólo en el sentido estricto de onerosidad, sino también en cuanto a inmovilización de bienes del deudor. Un ejemplo paradigmático de estos caracteres es la "garantía a primera demanda", que se introdujo en el mercado del crédito para evitar las solemnidades de las garantías tradicionales y la caución de títulos, que implicaba su inmovilización.

Este trabajo se propone echar una mirada global a las diferentes garantías, comparándolas, clasificándolas y analizando brevemente sus principales efectos ${ }^{5}$.

2. De acuerdo con el Diccionario de la Lengua Española, garantía es "efecto de afianzar lo estipulado" y, en un sentido más amplio, "cosa que protege y asegura contra algún riesgo o necesidad". Desde esta última perspectiva se habla de "garantías constitucionales", del patrimonio "como garantía común de los acreedores" y de "garantía

\footnotetext{
3 TRABUCCHI, Alberto, Istíluzioni di Diritto Civile, Cedam, Padova, $33^{a}$ edic, 1992, pág. 547.

${ }^{4} \mathrm{cfr}$. Primeras Jornadas de Derecho civil, Mendoza, 1983, Tema 1: Responsabilidad de las entidades financieras, Conclusión c) Existe responsabilidad extracontractual de la entidad financiera...5) Por el otorgamiento abusivo de crédito (se entiende por tal la creación de una apariencia de solvencia, inexistente en el deudor); CASIELLO, Juan José, Sobre la responsabilidad de los bancos por concesión abusiva de crédito, en Estudios de derecho privado modemo, Homenaje al Dr. Angel B. Chávarri, Ad-hoc, Bs.AS., 1998, pág.107.

${ }^{5} \mathrm{cfr}$. BUERES, Alberto, MAYO, Jorge A., Lineamientos generales sobre las "garantías" de la obligación en el Derecho privado, en Revista de Derecho privado y comunitario, Na 2 Garantías, pág. 7 y ss.; HIGHTON, Elena, Panorama del régimen de las garantías en el Derecho estadounidense, en Revista de Derecho privado y comunitario, $\mathrm{N}^{\mathrm{a}} 2$ Garantías, pág.189 y ss.

${ }^{6}$ Esa fórmula, aunque incorrecta en su origen, cuando se hablaba de la "prenda común de los acreedores", representó un notable progreso jurídico, porque, como dice LEVAGGI, Abelardo, Historia del Derecho de las obligaciones, contratos y cosas, Perrot, Bs.As., 1982, pág. 50, significó pasar de la responsabilidad personal por la que el deudor quedaba a merced del acreedor en su persona, a la responsabilidad patrimonial; de la vieja fórmula "del crédito por dinero responde el cuerpo" a la nueva "del crédito por dinero deben responder los bienes del deudor y no el cuerpo".
} 
patrimonial genérica"?

La palabra garantía suele emplearse indistintamente con el vocablo responsabilidad. Sin embargo, no son técnicamente sinónimos, pues, si bien ambas refieren al derecho de los acreedores a la satisfacción de sus razones ${ }^{8}$, se diferencian porque la responsabilidad consiste en el deber de responder para satisfacer al acreedor; mientras que garantía es asegurar a los acreedores un poder de agresión con relación a otros acreedores.

Por eso puede haber responsabilidad limitada con garantía genérica (caso del heredero con beneficio de inventario que responde sólo con los bienes recibidos del causante, pero genéricamente con todos ellos) y responsabilidad ilimitada con garantía específica (por ejemplo, el deudor hipotecario, que tiene responsabilidad ilimitada porque responde con todo su patrimonio en aquella parte del crédito que no cubra el bien hipotecado) ${ }^{9}$.

También, en un sentido amplio, pero con mayor especificidad, pueden mencionarse los siguientes institutos: cláusula penal, seña, privilegios, acciones reales y posesorias, acciones de simulación y revocatoria, derecho de retención, garantía de evicción, pacto de retroventa ${ }^{10}$.

En sentido restringido, Diez Picazo dice que garantía "es una norma de derecho o acto de autonomía privada que viene a añadir al crédito algo que el crédito por sí mismo no tiene, de tal manera que es esta adición o yuxtaposición lo que refuerza al acreedor la seguridad de que su derecho será satisfecho"11.

Se incluyen en este concepto las siguientes garantías: fianza, aval, obligaciones solidarias, hipoteca, prenda, anticresis, anotaciones voluntarias, "garantía a primera demanda"!2, fideicomiso de garantía, cesión en garantía,

\footnotetext{
7 BARBERO, Domenico, Sistema del Derecho privado, trad. S.Sentís Melendo, EJEA, Bs.As., 1967, tomo III, pág. 159.

${ }^{8}$ MESSINEO, Francesco, Manual de Derecho civil y comercial, trad. S. Sentís Melendo, EJEA.,Bs.As., 1971, tomo IV, pág. 60.

${ }^{9}$ idem., pág. 60

10 Una categorización diferente p.v. en FERNANDEZ, Raymundo L., GÓMEZ LEO, Osvaldo R., Tratado teórico-práctico de Derecho Comercial, Depalma, Bs.As., 1988, tomo III-c, pág. 9, quienes diferencian: garantía genérica (el patrimonio como garantía común de los acreedores) y garantia especifica (privilegios). Dentro de los privilegios incluyen prenda, hipoteca y anticresis y excluyen la fianza y la solidaridad a la que denominan seguridades personales.

11 DIEZ PICAZO, Luis, Fundamentos del derecho civil patrimonial, Tecnos, Madrid, 1970, vol. 1, pág. 571. 12 Según BIANCA, C. Massimo, PATTI, Guido y PATTI, Salvatore, Lessico di Diritto civile, Giuffrè, Milano, 1995, 2a.edic., pag. 509 estos negocios son, en general, negocios constitutivos de garantía personal no accesoria, o sea desvinculada de la relación garantida. En sentido específico, el negocio autónomo de garantia es un negocio atípico, mediante el cual un sujeto (normalmente un banco o una compañía de seguros) se obliga a título de garantía al primer requerimiento del acreedor a cumplir la prestación debida por el deudor o una prestación indemnizatoria, sin poder oponer excepción alguna en orden a la relación garantida.

Tan importante es la garantía a primera demanda que la Comisión de las Naciones Unidas para el Comercio Internacional, en 1996 se ocupó del asunto y redactó un Proyecto de Convención sobre las garantías independientes y las letras de crédito. P.v. un comentario en PIEDELIËVRE, Stéphane, Le projet de convention de la commission des Nations-Unies pour le commerce international sur les garanties indépendantes et les lettres de crédit stand-by, en Revue trimestrielle de droit commercial et de droit économique, 1996-4, pág. 633.
} 
"depósito en garantía"13, "mandato de crédito"14, "opción en garantía"15, y aun el denominado "contrato de garantía"16.

Para que opere la garantía en sentido estricto es necesario que exista:

1) Un bien a proteger, que será el objeto de la garantía. Puede ser una cosa o un derecho, aunque generalmente será un derecho de crédito.

2) Un riesgo que pueda afectarlo. Cuando se garantiza un derecho de crédito ese riesgo puede estar vinculado con la solvencia del obligado (que puede variar con el transcurso del tiempo, sobre todo si el crédito es a largo o mediano plazo), a las fluctuaciones de la moneda, a la conservación, devolución o pérdida de la cosa, etcétera.

3) Una persona encargada de impedir el daño (prevención) o responder por él, supletoriamente, si no pudiera evitarlo (seguridad) ${ }^{17}$.

La garantía en sentido estricto es una tutela ulterior a la garantía patrimonial genérica, que se agrega a ella ${ }^{18}$. Es esencialmente accesoria, ya que por definición, implica adicionar un plus al derecho de una persona. Es un nuevo derecho subjetivo o una nueva facultad ${ }^{19}$. Sin embargo, como se verá, existe ahora una marcada tendencia a concebirla como obligación principal, sobre todo en sus modalidades más novedosas.

Nos interesan los "negocios" de garantía, es decir, de acuerdo con el artículo 944 de nuestro Código civil, el hecho humano voluntario lícito que tiene por fin inmediato producir efectos jurídicos de garantía; o mejor, siguiendo la definición de Betti ${ }^{20}$, el acto con el cual una persona regula por sí sus intereses propios de seguridad en relación con otras y al que el derecho enlaza los efectos más conformes a esa función económica-social que caracteriza el tipo.

${ }^{13}$ Regulado expresamente en el art. 1773 del Código civil italiano. Es un depósito en interés de un tercero, con el cual se tiende a prevenir el peligro de dispersión de una prestación (de ordinario, de una suma de dinero) debida subordinadamente a la verificación de una condición 0 al vencimiento de un término. Se garantiza el derecho del tercero, MESSINEO, Francesco, op. cit., tomo $V$, pág. 272.

${ }_{14}$ Contrato por el cual una persona se obliga frente a otra, y a su pedido, a conceder crédito a un tercero en nombre y por cuenta propia, MESSINEO, Francesco, op. cit., tomo IV, pág. 140; BIANCA, C. Massimo, Diritto civile, Giuffrè, Milano, 1994, tomo 5, pág. 505. Esta interesante figura no está tipificada en nuestro derecho, pero sí está prevista en los arts. 1958 y 1959 del Código civil italiano y en el parag. 778 del BGB (Código civil alemán).

${ }^{15} \mathrm{cfr}$. FELIU REY, Manuel Ignacio, La prohibición del pacto comisorio y la opción en garantia, Civitas, Madrid, 1995, pág.31. Dice el autor que "el modus operandi" propio del derecho de opción, así como la posibilidad de su constancia registral y consiguiente eficacia erga omnes, le confieren unas perspectivas casi ilimitadas y de gran utilidad para su empleo como instrumento de garantía, de forma que, en caso de incumplimiento por el deudor, el acreedor-optante puede proceder a satisfacer su interés mediante el ejercicio del derecho de opción concedido a tal efecto, adquiriendo por el solo ejercicio de su voluntad el bien dado en garantia por el deudor". ${ }^{16}$ Contrato por el cual un contratante, para estimular una iniciativa del otro, asume sobre si todo o parte del riesgo que va ligado a la iniciativa, v. MESSINEO, Francesco, op. cit. pág. 82.

17 La idea de seguridad está presente con diferentes matices en todas las acepciones de la palabra garantía, como dice BOFFI BOGGERO, Luis M., Garantía por hecho ilícito ajeno, en Enciclopedia jurídica Omeba, voz Garantía.

${ }^{1 a}$ BIANCA, C. Massimo, op. cit., pág. 465.

19 DIEZ PICAZO, Luis, op. cit, pág. 571.

${ }^{20}$ BETTI, Emillo, Teoria general del negocio jurídico, ERDP., Madrid, 2a.edic. pág.51. 
Como es sabido, los actos o negocios jurídicos tienen un régimen propio que los códigos de fondo contemplan en la llamada teoría general del negocio jurídico y constituyen el paradigma de la autonomía de la voluntad, razón por la que el legislador y el intérprete deben hacer prevalecer en ellos la voluntad de las partes.

Esta cuestión de considerar la voluntad del otorgante se manifiesta en algunos negocios que son semejantes, aunque no iguales, a las garantías típicas. Entre nosotros, por ejemplo, la cuestión aparece en la carta de recomendación, que puede dar lugar a dudas acerca de si quien la otorga tiene voluntad de garantizar, o no, al recomendado. En principio, según los artículos 2007 a 2010 del Código civil, no constituye fianza, y quien la otorga de mala fe tiene sólo obligación de pagar daños y perjuicios, es decir; indemnizar, no garantizar (art. 2009). Sin embargo, a pesar de las normas, habrá que atender a la voluntad del otorgante, indagando si su propósito fue asumir una garantía respecto del recomendado o presentar una simple carta de recomendación. Sólo en el primer caso deberán aplicarse los principios de la fianza.

Las cartas de recomendación, transformadas ahora en lo que en el Derecho comparado se conoce como "negocio de patronato", tienen cada vez mayor importancia en los grandes negocios, especialmente en la obtención de financiamientos bancarios para sociedades coligadas. Dice Medicus que en Alemania, alrededor de 1965, se extendió en la economía una nuevo medio de garantía del crédito que consiste en que un tercero (el "patrono") manifiesta al dador del crédito que asistirá al tomador del mismo (al "protegido") con el reembolso. El patrono participa con el protegido (en especial como sociedad madre del consorcio) y por eso está interesado en la concesión del crédito ${ }^{21}$.

A pesar de sus peculiaridades, las garantías pueden ser analizadas en su conjunto, pues tienen en común la función de reforzamiento del crédito ${ }^{22}$, su pertenencia a la teoría general del negocio jurídico, y su carácter de fuentes de obligaciones. Esto hace que, ya sean típicas o atípicas, en caso de duda se les pueda aplicar las normas relativas a los actos jurídicos y a las obligaciones en general.

3. En sus orígenes las garantías eran personales ${ }^{23}$, y resultaban muy fuertes para los acreedores, porque les concedían la posibilidad de ejecución sobre la persona ${ }^{24}$.

En lo que concierne a las garantías reales, hay que decir, en primer lugar, que la prenda y la hipoteca no estaban en un principio bien diferenciadas, porque en el antiguo Derecho la prenda se asemejaba a la venta con pacto de retroventa y podía constituirse sobre muebles e inmuebles. Lentamente fueron diferenciándose ${ }^{25}$. Transcurrió mucho

21 MEDICUS, Dieter, Tratado de las relaciones obligacionales, trad. Angel Martínez Sarrión, Bosch, Barcelona, 1995, vol. 1, pág.618; TRABUCCHI, Alberto, op. cit, pág. 579.

22 BIANCA, C. Massimo, op. cit, pág. 465.

${ }^{23}$ RIPERT, Georges, BOULANGER, Jean, Tratado de Derecho civil según el Tratado de Planiol, trad. D.García Daireaux, La Ley, Bs.As., tomo VII, pág. 24.

${ }^{24}$ MAZEAUD, Henri, León y Jean, Lecciones de Derecho civil, trad. Alcalá-Zamora y Castillo, EJEA, Bs.As., 1962, Parte III, tomo 1, pág. 16.

${ }^{25}$ RIPERT, Georges, BOULANGER, Jean, op. cit., pág. 50. 
tiempo hasta que la hipoteca fue incorporada a los usos jurídicos, debido a que la ejecución hipotecaria en caso de incumplimiento concluye, como se sabe, en el remate del inmueble y en el derecho primitivo no se concebía la posibilidad de rematar inmuebles de los deudores sin su consentimiento ${ }^{26}$.

En la práctica el empleo de estas garantías estaba muy restringido porque, tanto la prenda como la hipoteca, cuando ésta fue receptada, exigían en todos los casos el desplazamiento de la cosa objeto de la garantía, por no admitirse que alguien tuviera derecho sobre ella sin poseerla.

Las garantías reales fueron admitiéndose y diferenciándose cuando el pensamiento científico llegó a un mayor grado de abstracción. Se necesitaba un derecho que hubiera evolucionado lo suficiente ${ }^{27}$ y un proceso de abstracción para reconocer que, sin la entrega de la cosa, pudiera constituirse un derecho real que facultara al acreedor a rematarla sin la voluntad del dueño. Se necesitaba evolucionar para elaborar la idea de que las garantías reales suponen una "enajenación virtual" del bien que gravan ${ }^{28}$, enajenación que cuenta con la voluntad del titular dominial manifestada en el momento del perfeccionamiento del contrato, de modo tal que al momento del incumplimiento la venta del bien dependa sólo de la voluntad del acreedor.

Para que las garantías reales adquirieran pleno desarrollo restaba darles seguridad mediante un régimen adecuado de publicidad frente a terceros. Para ello se necesitó una nueva evolución que admitiera la registración como suficiente publicidad, pues en un derecho no evolucionado, apegado a lo concreto, sólo podía concebirse la posesión como medio para hacer conocer a terceros los derechos reales.

En este lento proceso de desarrollo, cuando se alcanzó un grado todavía mayor de abstracción pudo reconocerse la garantía real, como significando un crédito real por oposición a crédito personal. Crédito real que permite al titular de la cosa "enajenar" en favor del acreedor el valor de ella en proporción al monto adeudado ${ }^{29}$.

A partir de allí, las garantías reales fueron adquiriendo prestigio y desplazando a las personales, que parecían ofrecer menos seguridad; a punto tal que los autores clásicos, aún los de mediados de este siglo, consideraron que la hipoteca era la garantía más segura y aconsejable ${ }^{30}$ llegando algunos a desacreditar profunda y extensamente las personales ${ }^{31}$.

\footnotetext{
${ }^{25}$ FERNANDEZ, Raymundo L., GOMEZ LEO, Osvaldo R., op. cit., pág. 22.

${ }^{27}$ MAZEAUD, Henri, León y Jean, op. cit., pág. 16.

${ }^{28}$ MESSINEO, Francesco, op. cit., tomo IV, pág. 79.

${ }^{29}$ FERNANDEZ, Raymundo L., GOMEZ LEO, Osvaido R., op. cit, pág. 36.

${ }^{30}$ MAZEAUD, Henri, León y Jean, op. cit., pág. 19 dicen "Por ser la hipoteca la más perfecta de las garantías...."; BARBERO, Doménico, op. cit., pág. 164 dice "el más alto grado de seguridad" pero agrega "(aunque siempre relativa)", es decir que va reconociendo los límites.

${ }^{31}$ Tal como lo hace PUIG PEÑA, t.4, vol. 2, pag. 478 citado extensamente por BORDA, Guillermo A., Tratado de Derecho Civil, Contratos, Perrot, Bs.As., 7a. edic. actualizada, t. II, pág. 443: "A pesar de esta vieja historia la garantía personal es figura totalmente desacreditada. ...fomenta, por así decirlo, en la persona del deudor (en la mayoría de los casos) una situación de apatía e inmoralidad, incitándole a declarar su irresponsabilidad en perjuicio del fiador....Desde el punto de vista social hace de la amistad un instrumento peligroso y abusivo, porque el deudor se atreve con más facilidad a exigir del amigo la garantía que el contenido económico de la obligación garantizada; ..."
} 
En la actualidad el criterio está variando, pues la agilidad de los negocios exige una flexibilidad que las garantías reales y, en especial, la hipoteca, no ofrecen en materia de plazos y montos, determinación de las obligaciones garantizadas y costos de constitución.

Puede decirse entonces que el derecho de las garantías se ha ido formando lentamente por los aportes sucesivos de la técnica jurídica, según Ripert y Boulanger ${ }^{32}, y$ que en materia de abstracción estamos llegando en este tiempo a los mayores despliegues, pues ya no interesa tanto al acreedor tomar "cosas" en garantía sino, algo menos concreto, como son los "derechos".

En la práctica económica, es cada vez más frecuente el empleo de los títulos de crédito vinculados a derechos reales de garantía (pagarés hipotecarios, cédulas y letras hipotecarias), que están claramente fundados en una abstracción: la separación de la cosa y su valor ${ }^{33}$. Esta modalidad permite una gran celeridad no sólo en la constitución y ejecución de la garantía, sino también en la circulación y transmisibilidad de los papeles, haciendo que el acreedor tenga, más que un deudor, una cadena de deudores.

También son frecuentemente utilizadas las garantías reales constituidas sobre títulos de crédito, como prenda de pagarés, o sobre títulos en gestión patrimonial. Siguiendo la tendencia de la práctica, la jurisprudencia nacional ha admitido la constitución de prenda sobre cheques corrientes. En nuestra opinión, puede ser factible la prenda sobre cheques de pago diferido ${ }^{34}$ porque en cierta medida son instrumentos de crédito, pero es erróneo admitirla respec to de los otros cheques, que son instrumentos de pago. Y es así, no sólo por la propia naturaleza del cheque sino también por las dificultades que se presentan cuando, ante el incumplimiento de la obligación garantizada, se hace necesaria la ejecución de la prenda ${ }^{35}$. En definitiva, creemos que, si se reconoce la posibilidad de prendar cheques, habrá que calificar a tal contrato de "prenda anómala" con efectos diferentes a los de la prenda típica ${ }^{36}$.

En la evolución que estamos describiendo hay que señalar otro fenómeno actual, manifestado especialmente en la fianza. Se trata del paso de la garantía gratuitá, prestada por amistad, a la garantía onerosa, ofrecida "profesionalmente" como servicio remunerado, que no se otorga para prestar un favor con miras a facilitar la obtención de crédito, sino como un nuevo y rentable servicio que permite obtener lucro ${ }^{37}$.

\footnotetext{
${ }^{32}$ RIPERT, Georges, BOULANGER, Jean, op. cit. pág. 16.

${ }^{33}$ FERNANDEZ, Raymundo L., GOMEZ LEO, Osvaldo R., op. cit., pág.36

${ }^{34}$ MugulLLO, R.A., Prenda con registro, Astrea, Bs.As., 1997, pág. 110.

${ }^{35}$ En el caso "Neuberger Hnos. S.A.- Concurso preventivo", C.N.Com., Sala D, 27 oct. 1994, L.L.1995-C, 202, el acreedor prendario cobró cheques prendados y compensó deudas, lo que significó "apropiarse" del producido, cuestión prohibida en el régimen prendario. Lo que debieron hacer fue ejecutar los cheques judicialmente, según opina Ricardo NISSEN en el comentario a dicho fallo: Prenda de documentos y facultades del Banco frente al concurso preventivo de la deudora prendaria. Por su lado, MESSINEO, Francesco, op. cit., tomo IV, pág. 95 no admite la prenda de cheques por la brevedad de su vida.

${ }_{3 \in}$ TRABUCCHI, Alberto, op. cit, pág. 585.

${ }_{37}$ TRABUCCHI, Alberto, op. cit, pág. 579, dice que "la fantasía creadora de los operadores económicos" dio origen a "consorcios de garantía colectiva", con apoyo oficial o no, a "cooperativas de garantia" para artesanos, e incluso para favorecer a las pequeñas y medianas empresas se constituyen "fondos de riesgo", con el aporte de modestas contribuciones.
} 
Por último como se verá más adelante, en esta materia observamos también la influencia de la masificación negocial, que hace que los negocios se perfeccionen frecuentemente por adhesión y sin un conocimiento "personal" del garante.

4. Todos los negocios de garantía tienen por finalidad reforzar el crédito, pero cumplen esa función de manera diversa, según las diferentes estructuras y contenidos que posean ${ }^{38}$, por eso es posible y necesario clasificarlos desde diferentes puntos de vista. La clasificación que sigue permite compararlos, diferenciarlos y comprenderlos mejor en su significado y efectos jurídicos.

a) Según la fuente, las garantías pueden ser legales o convencionales ${ }^{39}$.

Las garantías legales, como su nombre lo indica, son establecidas por la ley, están a cargo del Estado o de entes públicos, y tienen fines de seguridad macroeconómicos o de interés general (por ejemplo, la garantía de los depósitos bancarios) ${ }^{40}$. Algunas veces surgen directamente del texto legal y, en otros casos, en cambio, el texto autoriza a los entes públicos a emitirlas ${ }^{4}$.

Pueden también estar a cargo de particulares y en favor de determinadas personas (por ejemplo, la fianza legal o la hipoteca legal en los países que la admiten). Del mismo modo que en las garantías a cargo del Estado, puede suceder que la ley ordene el otorgamiento de la fianza ${ }^{42}$ o que, excepcionalmente, considere que la relación de fianza está constituida ex lege, en razón de que la persona a la que la ley declara fiadora se encuentra en una determinada posición jurídica, sin que haga falta un acto de otorgamiento posterior ${ }^{43}$. En el primer caso, si bien la obligación de prestar fianza tiene su fuente en la ley, la fianza en sí misma tiene su fuente en la voluntad unilateral del fiador que se obliga. Es, por tanto, un negocio jurídico no contractual sino unilateral, porque no requiere la conformidad del acreedor. En principio, entonces, resulta inadecuada la expresión del artículo 1998 del Código civil que dice "cuando la fianza sea impuesta por la ley", pues

\footnotetext{
${ }^{38}$ BIANCA, C. Massimo, op. cit., pág. 465.

${ }^{39}$ RIPERT, Georges, BOULANGER, Jean, op. cit., pág. 19 sostienen que "todas las garantías son legales en el sentido que para conceder a una persona un derecho que pueda ser oponible a todos es necesario que la ley determine las prerrogativas conferidas al acreedor". No parece exacta esta apreciación respecto de las garantías convencionales y personales que tienen su fuente en el negocio jurídico y pueden prescindir de toda ley al respecto.

${ }^{40} \mathrm{La}$ Corte Suprema de Justicia de la Nación, 23 feb. 1995, autos "Caja Complementaria de Prev. para el Personal de la Jurisdicción Comunicaciones c/ Provincia de La Rioja y otro", LL.1995. $\mathrm{C}, 195$, ha dicho que la garantía legal de los depósitos bancarios "no deriva del contrato de depósito bancario sino de la ley, ha sido impuesta con fines de regulación económica, no se trata de una garantía personal constituida para asegurar el pago de una obligación concreta, sino que es una responsabilidad de carácter general e indeterminada establecida para efectivizar la liquidación del banco y que no participa, en suma, de las características que configuran a la flanza regulada en el derecho común. Fallos:307:534".

41 BIANCA, C. Massimo, op. cit., pág. 470.

42 P.V. algunos casos de fianza legal en LOPEZ DE ZAVALIA, Fernando J., Teoría de los contratos, Zavalía, Bs.As., 1995, tomo 5, pág. 29.

${ }_{43}$ LOPEZ DE ZAVALIA, Fernando J., op. cit., pág. 23.
} 
dicha norma no obliga a nadie a constituirse como fiador, sino que obliga a determinadas personas a ofrecer un fiador quien, a su vez, se obligará voluntariamente.

La fianza legal está prevista junto a la judicial en el artículo 1998 del Código civil, ya mencionado.

Las garantías convencionales, por su parte, tienen su fuente en negocios jurídicos, tales como la hipoteca ${ }^{44}$, la prenda, la fianza y el aval.

Usualmente, las garantías legales son generales, en el sentido que se fija más adelante en el parágrafo 4.h), y personales, por oposición a reales, dado que se responde con todo el patrimonio y no se afecta un bien determinado ${ }^{45}$.

Diferenciar las garantías legales de las convencionales es útil para aplicar a estas últimas los institutos propios de la teoría general de los actos o negocios jurídicos y, a las primeras, las normas propias de la ley que las crea.

b) Según que lo que se comprometa en garantía sea una cosa o un nuevo deudor pueden ser reales (o sobre bienes) ${ }^{46}$ opersonales.

Garantía real es aquella que "sobre una o más cosas, del deudor mismo o de un tercero, asegura a un acreedor la posibilidad de satisfacerse con preferencia y con precedencia sobre otros" y garantía personal la que se otorga "cuando otra u otras personas se constituyen responsables, subsidiaria o solidariamente con el deudor principal, en caso de incumplimiento, es decir, que se comprometen a responder por él, con todos sus bienes, de las consecuencias del incumplimiento" ${ }^{\prime 2}$.

Esta tradicional clasificación incluye entre las garantías reales la hipoteca, la prenda, la anticresis y el warrant; y, entre las personales, la fianza, el aval y la solidaridad.

Las garantías reales típicas son la prenda (arts. 3204 a 3238 del Código civil y 580 a 588 del Código de Comercio y el decreto ley $15348 / 46$ ratificado por ley № 12962 , t.o. dec.897/95), la hipoteca (arts. 3108 a 3203 del Código civil) y el warrant.

Según Femández y Gómez Leo de esas garantías se derivan otras a las que pueden aplicarse supletoriamente sus principios. De la prenda con desplazamiento se derivan la prenda sobre muebles, la prenda civil, la prenda comercial y el warranty sobre inmuebles la anticresis. De la hipoteca se derivan, sobre inmuebles, la hipoteca propiamente dicha, y, sobre muebles, la hipoteca naval, la prenda con registro y el debenture $e^{48}$.

En la garantía real se liga una cosa al crédito y se acuerda un privilegio especial sobre ella, otorgándose al acreedor derecho de prelación y derecho de persecución respecto

\footnotetext{
${ }^{44}$ En el Derecho comparado se admite la categoría de hipoteca legal, pero en nuestro ordenamiento es sólo convencional, dado que Vélez Sársfield expresamente la desestimó.

${ }^{45}$ Por eso no es feliz la expresión empleada en el fallo citado en la nota 40 cuando se dice que la garantía legal de los depósitos bancarios "no es una garantía personal constituida para asegurar el pago de una obligación concreta". En ese caso el término "personal" no refiere a la garantia del Estado, sino al crédito garantizado y más concretamente a la persona del garantizado. 46 BIANCA, C. Massimo, op. cit., pág. 466.

47 BARBERO, Doménico, op. cit., pág. 164.

48 FERNANDEZ, Raymundo L., GOMEZ LEO, Osvaldo R., op. cit., pág. 35
} 
de la cosa. En la garantía personal, en cambio, se ligan una persona y su patrimonio, pero no hay privilegios especiales.

La constitución de una garantía real no modifica la naturaleza de la obligación garantizada, pues son negocios diferentes. Aunque haya conexidad entre ambos, ello no significa que su naturaleza pueda sufrir modificación alguna ${ }^{49}$. Si bien la conexidad negocial no produce precisamente ese efecto, permite en cambio que, en la realidad social, el negocio garantizado se beneficie de la garantía, adquiriendo casi su misma fuerza, aunque esta última no aproveche del garantizado ${ }^{50}$ (por ejemplo, el mutuo garantizado con hipoteca adquiere la misma fuerza de ésta, tanto que a veces se confunden, pero la hipoteca no cambia en nada por el mutuo).

Una clásica y debatida cuestión es si las garantías teales son derechos reales. Hay quienes niegan esa naturaleza ${ }^{51}$, aun entre nosotros ${ }^{52}$. Por nuestra parte, creemos que, si bien en algunos ordenamientos, como el italiano, la cuestión puede ser discutible por no haber normas al respecto, en el derecho argentino ello no es posible porque el artículo 2503 del Código civil incluye expresamente la prenda, la hipoteca y el anticresis en el número clausus de los derechos reales, con carácter de orden público. Aun cuando científicamente se pueda compartir la opinión de quienes entienden que no son derechos reales, mientras esté vigente el régimen actual, en nuestro país habrá que considerarlas de este modo. Pero aunque no fueran derechos reales tendrían siempre naturaleza de derecho sustancial y no procesal, como pretendió Carneluttii ${ }^{53}$.

c) Según las partes del negocio, las garantías pueden ser unilaterales o bilaterales.

Son unilaterales cuando se constituyen por la voluntad de una sola parte, como la fianza legal o judicial y los embargos e inhibiciones voluntarias. Son bilaterales cuando para su perfeccionamiento se requiere la voluntad de dos partes, como la hipoteca o la fianza.

En cuanto al carácter bilateral de algunas garantías, como la hipoteca y la moderna "garantía a primera demanda", no hay consenso en la doctrina, aunque parece acertado considerarlas contratos, teniendo en cuenta que el acreedor puede manifestar directamente su aceptación de la propuesta de garantía, o indirectamente, por comportamientos declarativos o no. Generalmente lo hace de ese modo, por aceptación tácita, según la terminología del Código civil (art. 1145) ${ }^{54}$.

\footnotetext{
${ }^{49}$ RIPERT, Georges, BOULANGER, Jean, op. cit., pág. 21.

${ }^{50}$ MESSINEO, Francesco, op. cit., tomo IV, pág. 80.

51 BARBERO, Doménico, op. cit. pág. 193; en cambio otros la reconocen como MESSINEO, Francesco, op. cit., tomo IV, pág.74.

${ }^{52}$ FERNANDEZ, Raymundo L., GOMEZ LEO, Osvaldo R., op. cit., pág. 44.

${ }^{53}$ Como dijo MESSINEO, Francesco, op. cit., torno IV, pág. 77, los deberes propios de las garantías reales "no encuentran una explicación fuera del derecho sustancial, tanto menos aún cuanto que operan antes y prescindiendo de la ejecución forzada sobre el bien dado en garantia; y no está permitido pasarlos por alto".

${ }^{54}$ Entre nosotros se la incluyó dentro de las declaraciones unilaterales de voluntad bajo el nombre de "Garantías unilaterales autónomas" en el artículo 1479 del Proyecto de reformas al Código civil elaborado por la Comisión designada por decreto 468/92.
} 
Interesa diferenciar los negocios unilaterales de los bilaterales porque hay institutos que sólo son aplicables a estos últimos (excepción de incumplimiento, facultad comisoria, etc.). Respecto de la facultad comisoria en la hipoteca y la prenda, que procedería en principio por ser contratos con prestaciones recíprocas (art. 1204 del Código civil), debe tenerse en cuenta que su aplicación está prohibida, tanto en nuestro Derecho como en muchos otros, para evitar que el acreedor abuse obteniendo una ventaja indebida mediante la apropiación de un bien cuyo valor supere al crédito ${ }^{55}$.

d) Desde el punto de vista de su regulación legal, pueden ser típicas o atípicas.

Corresponden al primer grupo las que tienen regulación legislativa (en nuestro Derecho: la fianza, la hipoteca, la prenda, la anticresis, el aval, el warrant y el fideicomiso de garantía). Son atípicas cuando han sido libradas a la autonomía de la voluntad, como sucede en el ordenamiento argentino con la "garantía a primera demanda", cesión en garantía y el "mandato de crédito".

En cuanto al derecho aplicable a las garantías atípicas, habrá que diferenciar si gozan o no de tipicidad social, es decir, si, a pesar de no tener regulación legal, son realizadas habitualmente en el lugar de celebración. En el primer supuesto deben aplicarse con preferencia los usos, mientras no se trate de usos abusivos impuestos por negociaciones predispuestas. En cambio, si ni siquiera gozan de tipicidad social, deben ser regidos con preferencia por los principios generales de las obligaciones y contratos y luego por la regulación de los contratos más afines ${ }^{56}$.

El orden de preferencia que apuntamos es el más justo a nuestro entender porque permite que no se desnaturalice la voluntad de las partes. Así, en caso de conflicto, no podría aplicarse a una "garantía a primera demanda" el régimen del contrato más afín, el de fianza, porque el principio de accesoriedad característico de este contrato, los diferencia sustancialmente ${ }^{57}$.

e) Según que deba el acreedor efectuar o no un sacrificio para obtener la ventaja de la garantía, se clasifican en onerosas o gratuitas.

En las garantías por el hecho ajeno (v. parágrafo 4.i)), cuando el deudor principal es qquien realiza el sacrificio compensando al garante, el negocio resulta gratuito y la onerosidad sólo estará referida al vínculo que une al deudor con el garante ${ }^{58}$. En esos negocios es habitual que el interesado sea el deudor principal, pues el otorgamiento de la garantía le permite conseguir crédito y por eso paga al fiador ${ }^{59}$.

\footnotetext{
55 BARBERO, Doménico, op. cit., pág. 186; MESSINEO, Francesco, op. cił., tomo IV, pág. 82, funda la prohibición en la sospecha de que el pacto oculta la usura en daño del deudor.

${ }^{56}$ cfr. Conclusiones Comisión № 3 XII Jornadas Nacionales de Derecho Civil, Bariloche, 1989; ALTERINI, Atilio A., Contralos. Teoría general, Abeledo Perrot, Bs. As., 1998, pág. 189.

57 P.v. el caso citado por SCHMIDT-SZALEWSKI, Joanna, Droit des contrats, Litec, Paris, 1989, pág. 290, Com.20 déc.1982: Bull.civ.IV, n.417.

${ }^{58}$ MESSINEO, Francesco, op. cit, tomo IV, pág.80.

${ }^{59}$ MEDICUS, Dieter, op. cit., pág. 611.
} 
Tradicionalmente, las garantías fueron gratuitas, sobre todo en el Derecho civil, porque, como se dijo, eran un acto de amistad, un servicio que se prestaba a un amigo o un familiar; pero en la actualidad, son ofrecidas como servicios por entidades financieras $y$, por tanto, son onerosas.

La diferencia entre garantías gratuitas y onerosas importa porque las primeras pueden ser atacadas por los acreedores mediante acción revocatoria, con la simple acreditación del perjuicio, sin necesidad de prueba de la intención fraudulenta (art. del 962 Código civil) y porque no se aplican los principios de la evicción y vicios redhibitorios (arts. 2089 y 2164 del Código civil).

f) Según que el negocio utilizado por las partes tenga o no por finalidad inmediata la constitución de garantía, se clasifican en directas o indirectas.

Garantía directa es aquella en la que el resultado práctico, el aseguramiento, es querido en forma inmediata con el negocio correspondiente (hipoteca, fianza, aval); e indirecta es la que, para obtener la finalidad práctica de asegurar, aprovecha un tipo negocial que tiene una finalidad distinta ${ }^{60}$. Pertenecen a esta categoría el fideicomiso de garantía, el mandato con fines de garantía, el mandato de crédito, la opción en garantía $y$, en general, los negocios fiduciarios con fines de garantía ${ }^{6 !}$.

g) Según el grado de autonomía que posea la garantía con relación a la obligación afianzada, pueden ser principales o accesorias.

Esta clasificación aparece en nuestro Código civil respecto de las obligaciones (arts. 523 a 526) y no de los negocios jurídicos; pero por analogía tales normas pueden aplicarse a los negocios accesorios ${ }^{62}$.

Son garantías principales la solidaridad y la "garantía a primera demanda" clásica (pues hay otras especies que no son principales: a primera demanda justificada, o a primera demanda con prueba del incumplimiento); y accesorias, la fianza, la hipoteca y la prenda.

Como los negocios de garantía son por lo común accesorios, se aplica el principio general de que lo accesorio sigue la suerte de lo principal. Por esa razón el negocio accesorio se extingue cuando se extingue el principal, cuestión no resuelta en nuestro Código por una norma general común a todas las garantías, similar al artículo 1275 del Código civil italiano, que dice: "Extinción de las garantías. En todos los casos en los que el acreedor libera al deudor originario, se extinguen las garantias anexas al crédito, si aquel que las ha prestado no consiente expresamente en mantenerlas".

\footnotetext{
${ }^{60} \mathrm{BETTI}$, Emilio, op. cit., pág. 235 dice que negocio indirecto es el que aprovecha un tipo de negocio para la consecución de un fin distinto de aquél que su causa típica representa.

61 Acerca de los negocios fiduciarios, p.v. RUBINO, Domenico, El negocio jurídico indirecto, trad. L. Rodríguez Arias, EJEA, Madrid, 1953; GALGANO, Francesco, I/ negozio giuridico, Giuffrè, Milano, 1988, pág. 424; BREBBIA, Roberto $\mathrm{H}$., Hechos y actos jurídicos, Astrea, Bs. As., tomo 2, 1995, păg. 70 .

${ }^{62}$ COMPAGNUCCI DE CASO, Rubén H., El negocio jurídico, Astrea, Bs.As,, 1992, pág.93.
} 
Esta carencia normativa que apuntamos no influye en las garantías típicas, ya que cada una de ellas tiene expresamente reguladas las causales de extinción (por ejemplo, en la fianza, los arts. 2042 y ss.; en la hipoteca los arts. 3187 y ss.; y en la prenda los arts. 3236 al 3238 del Código civil); pero se hace sentir en las atípicas.

El principio general al que venimos refiriéndonos tiene excepciones. En nuestro Derecho, si la obligación afianzada es nula en razón de la incapacidad del deudor, el fiador queda como obligado principal (art. 1994 del Código civil). Si el contrato afianzado se anula por otras razones, será nula también la fianza, sin perjuicio de que pueda tener alguna eficacia. Los efectos restitutorios y resarcitorios de la nulidad (arts. 1052 a 1056 del Código Civil) del contrato principal se extienden también al contrato accesorio, de tal manera que el fiador responde cuando se anula el contrato y el deudor no cumple restituyendo las prestaciones recibidas, y también cuando corresponde indemnizar los daños y perjuicios precontractuales por haber sido el deudor responsable de la anulación ${ }^{63}$.

Actualmente hay una marcada resistencia a la accesoriedad, que se manifiesta en la fianza de dos maneras: una muy simple, que es el empleo de la figura del principal pagador (art. 2005 Código civil), y otra, muy sofisticada, reservada para las grandes operaciones, que es la nueva figura de la "garantía a primera demanda". Gradualmente, se va convirtiendo la garantía en negocio principal y, por tanto, autónomo, con independencia de vínculos.

La "garantía a primera demanda" es autónoma porque no depende de la existencia o de la validez de una operación subyacente, ni de otra obligación, garantía o condición (por ejemplo, no es garantía a primera demanda la que se condiciona a la "llegada de un barco a puerto"). Sólo aparece un resto de accesoriedad en la acción de regreso contra el deudor garantizado.

Como se dijo, entre nosotros la "garantía a primera demanda" es atípica y sin tipicidad social, por lo que interesa tener en cuenta los precedentes del derecho comparado. La Corte italiana, por ejemplo, ha dicho que es un negocio atípico, pero referible a la relación de fianza, en cuanto es una garantía; y que, en realidad, sólo implica una inversión de la carga de la prueba. En otro caso resolvió que, si bien es una "garantía" autónoma, no es una "obligación" autónoma, privada de causa, sino que la causa de la obligación del garante a primera demanda es precisamente la obligación principal ${ }^{64}$. En Francia, donde se ha comenzado a usar frecuentemente en el régimen bancario, los tribunales son muy

\footnotetext{
${ }^{33}$ De este modo fue resuelto el caso comentado por SCHMIDT-SZALEWSKI, Joanna,op. cit., pág. 236: Se trataba de una fianza otorgada por los esposos Trivin en favor de Mobil Oil Française, para garantizar el contrato de "locación-gerencia" suscripto con dicha empresa por los esposos Denis Oliveira. Se solicitó la nulidad del contrato principal y de la fianza por ser su accesorio, sin embargo, el tribunal de casación dijo que la fianza no podría ser privada de eficacia retroactivamente, en relación a los suministros puntuales de los productos que la sociedad entregó a los locatarios gerentes a un precio aceptado por ellos (Com.4 fev.1986: Bull.civ.IV,n.1). ${ }_{64} \mathrm{cfr}$. PONTIROLI, Luciano, "Le clausole di "pagamento a prima richiesta" e di "Sopravvivenza": dalla giurisprudenza recente della Corte di Cassazione al provvedimento della Banca d'ltalia sulle N.B.U.", en Banca, Borsa e titoli di credito, 1996, 1, pág. 110 y 111.
} 
celosos en cuanto a resguardar la autonomía del contrato, para lo cual sus sentencias analizan de manera exhaustiva ese carácter, pues no siempre lo que se califica como garantía a primera demanda es tal.

h) Según se afecte al cumplimiento de la garantía el patrimonio del deudor o bienes determinados del mismo, pueden clasificarse en generales o especiales.

Son generales la fianza, la solidaridad, el aval, la garantía de evicción; y especiales, la hipoteca y la prenda.

i) Según que la obligación garantizada sea propia o ajena, habrá garantía por el hecho propio o por el hecho ajeno ${ }^{65}$.

En el primer grupo, se incluyen la hipoteca, la prenda, y la anticresis (aunque también pueden constituirse para afianzar obligaciones de terceros) y el depósito en garantía ${ }^{66}$.

Entre las garantías por el hecho ajeno pueden mencionarse la fianza, el aval, la "garantía a primera demanda" y la solidaridad. Boffi Boggero enuncia las siguientes: garantía del fiador, hipoteca para el caso de incumplimiento de obligaciones de un tercero, garantía del tercero a quien se entregó la cosa del deudor prendario, garantía del deudor anticresista en hipótesis similar a la anterior, garantía de los deudores solidarios entre sí, garantía del principal por el hecho de su subordinado ${ }^{67}$.

Interesa diferenciar las garantías por el hecho propio de las garantías por el hecho ajeno, dado que en estas últimas hay que considerar, no sólo la relación entre acreedor y garante, sino también entre garante y deudor principal.

j) Según quien sea el encargado de conducir el proceso de ejecución forzada de la garantía, pueden clasificarse como garantías con liquidación judicial o garantías autoliquidables.

En el primer caso el acreedor tiene sólo la vía de la ejecución judicial, como tradicionalmente aconteció en la hipoteca. Las garantías autoliquidables ${ }^{68}$, en cambio, autorizan al acreedor a ejecutar extrajudicialmente la garantía o a percibir directamente el crédito. Entre otros muchos supuestos, pertenecen a esta categoría, la prenda, la hipoteca (de acuerdo a los arts. 57 y ss. de la ley № 24.441) y el mandato con fines de garantía, cuando el acreedor se constituye como mandatario de su deudor para el cobro de sus créditos y es autorizado por éste para cobrarse su propio crédito de lo percibido.

\footnotetext{
${ }^{65} \mathrm{cfr}$. BOFFI BOGGERO, Luis María, op. cit.

${ }^{66}$ Este contrato es garantía por el hecho propio, pero implica un contrato a favor de tercero porque el depositario entrega la cosa al depositante no en su interés sino en el del tercero, para garantizar algún derecho de éste.

${ }_{67}$ Este supuesto no sería a nuestro parecer un supuesto de garantía, sino de responsabilidad. Acerca del tema p.v. MEZA, Jorge, BORAGINA, Juan Carlos, AGOGLIA, María M., Responsabilidad por hecho ajeno, Depalma, Bs.As., 1995.

${ }^{68}$ cfr. ALEGRIA, Héctor, Las garantías "autoliquidables", en Revista de derecho privado y comunitario, №2, Garantías, pág. 149.
} 
k) Según las seguridades que ofrecen para la percepción íntegra y en tiempo del crédito asegurado, las garantías pueden ser fuertes o débiles.

Son fuertes aquellas que posibilitan realmente al acreedor percibir su crédito y hacerlo con rapidez, como las garantías autoliquidables y las especiales. Más débiles son las garantías generales y las que exigen liquidación judicial.

Sin embargo, hay que tener en cuenta que aun las más fuertes pueden desbaratar las expectativas del acreedor de un día para otro. Por ejemplo, las especiales y autoliquidables pueden frustrarse, simplemente por la destrucción de la cosa gravada, razón por la cual, para evitar el perjuicio del acreedor, es necesario un reaseguramiento, como la toma de un seguro por el dueño de la cosa, endosado en favor de aquél.

1) Según las exigencias legales para el perfeccionamiento del negocio de garantía, pueden ser flexibles o inflexibles.

Son flexibles la fianza y el aval. Los requisitos legales de la fianza son escasos. Como es sabido, en materia de forma sólo se exige la forma escrita para la prueba, pero puede celebrarse aun verbalmente (art. 2006 Código civil); y se admite la fianza sin monto y respecto de cualquier obligación, exigiéndose sólo la determinación de su objeto (art. 1989 del Código civil).

En cambio, la hipoteca es inflexible, especialmente en el régimen del Código. Hay que recordar el largo camino transitado por la doctrina y la jurisprudencia, en plena época de inflación, para lograr alguna flexibilidad de las cláusulas de reajuste y llegar a las denominadas hipotecas abiertas o a la hipoteca como garantía del contrato de apertura de cuenta corriente bancaria.

También el régimen de la prenda es rígido, por ejemplo, en materia de objeto. Se discute todavía si procede la prenda sobre derechos, es decir, si puede constituirse el derecho real sobre derechos creditorios ${ }^{69}$. Es por ello que, quienes se esfuerzan por recuperar la vigencia de la prenda, proponen reformas tendientes a satisfacer requerimientos de mayor flexibilidad ${ }^{70}$.

La falta de flexibilidad en las formalidades incide en los gastos de constitución de las garantías, tornándolas, a veces, muy costosas con relación al valor del crédito ${ }^{71}$, todo lo cual lleva a que, en los meganegocios, se recurra con frecuencia a la garantía a primera

\footnotetext{
${ }^{69}$ BUERES, Alberto y MAYO, Jorge, op, cit., pág.26.

$70 \mathrm{cfr}$. ROBIOLO, Jorge $A_{1}$, Ley de prendas con registro. Sus reformas, en Estudios de derecho privado moderno, Homenaje al Dr. Angel B. Chávarri, Ad-hoc, Bs.AS., 1998, pág. 435 y ss.

71 Esto fue bien valorado en el voto del Dr. Alberti en autos "Pertenecer S.A.-Bases técnicas", CNCom., sala D, 14 nov.1995, LL. 1996-D, 7, cuando analizó: "Pero es igualmente innegable, desde el punto de vista económico, que los actuales costos de constitución y registro de los contratos destinados a establecer convencionalmente el derecho prendario pueden resultar excesivos con relación a la modesta operatoria consistente en ahorrar para adquirir los objetos de uso personal llamados corrientemente "electrodomésticos", pues esta es la actividad de la apelante".
} 
demanda, que es personal, atípica y flexible, a los "negocios autónomos de garantía" o a negocios de patronato; $y$, en los micronegocios, se reemplace la prenda por el pagarén

A pesar de las resistencias que se encuentren en la realidad económica, parece lógico que, para llegar a un régimen equilibrado, deba tenderse a que cuanto más fuerte sea una garantía, menor sea su flexibilidad, pues de ese modo se protege al acreedor, pero se lo controla haciéndole cumplir requisitos precisos. Por eso hay que esforzarse para que la moderna "garantía a primera demanda" que es muy fuerte, sea inflexible en algunos elementos, como el objeto y el plazo ${ }^{73}$.

5. Los negocios de garantía adoptan en la actualidad modalidades peculiares que merecen ser mencionadas. En primer lugar, hay que destacar que generalmente se constituyen como negocios predispuestos, es decir el acreedor predispone el contrato y quien garantiza, adhiere. Además es frecuente encontrar garantías, especialmente las bancarias, sometidas a condiciones generales de contratación.

Por tanto, existiendo en la realidad económico-social diferente poder de negociación, el negocio de garantía sometido a esas modalidades debe interpretarse considerando la debilidad jurídica del suje to que garantiza. Esto ocurre en los países desarrollados, con economías de mercado que admiten una intervención equilibrada en el contrato. En Italia, por ejemplo, se considera legítimo aplicar a esos contratos la disciplina del contrato por adhesión a condiciones generales, aunque sea entre empresas. Y aun más, la propia banca italiana se ha preocupado por proteger al garante por adhesión. En cambio, en el Derecho argentino todavía falta mucho por hacer al respecto, pues en algunos casos los criterios jurisprudenciales han sido exactamente los inversos ${ }^{74}$.

Otra modalidad contractual que se emplea en el ámbito de las garantías es la subcontratación, que posibilita a una de las partes de un contrato (denominado contrato base) celebrar con un tercero, otro contrato (denominado derivado) que tiene por objeto elementos de aquél. Existe subcontratación cuando se constituye un garante del garante en la "garantía a primera demanda", cosa que ocurre cuando el emisor es un banco que

\footnotetext{
72 Lo que fue autorizado por el tribunal en el fallo citado en la nota precedente. Teniendo en cuenta los valores económicos en juego y contra la opinión del órgano de control, ordenó la modificación de las condiciones generales de contratación en un contrato de ahorro para fines determinados.

${ }^{73}$ En el orden internacional esta cuestión constituye una verdadera preocupación. Así en materia de objeto el Proyecto de la Comisión de las Naciones Unidas para el comercio internacional citado en nota 12, admite que el monto pueda ser determinable pero la doctrina lo ha cuestionado con argumentos serios, V. PIEDELIÉVRE, S., op. cit., pág. 637. En cuanto al plazo el mencionado Proyecto exige que sea determinado, si no lo es la norma fija un plazo máximo de seis años. 74 v. C.N.Com., Sala C, 22 dic.1994, autos "Banco del Oeste S.A. en liq. c/ Calleja, Walter y otros" LL. 1996-A, 493, donde se dijo: "No basta en el caso la mera alegación de tratarse de un contrato por adhesión para que se disipen los efectos del vínculo. Nada se ha dicho, además, acerca del modo cómo se llevaron a cabo las negociaciones de los contratos de fianza, ni se ha invocado ninguna circunstancia concreta que, vinculada con la capacidad o el discernimiento de los fiadores, o con una eventual ligereza, inexperiencia o estado de necesidad, hubiera podido afectar el otorgamiento del acto desde el punto de vista jurídico".
} 
tiene un contragarante, ocuando se otorga una subfianza, que resulta ser un contrato accesorio de otro accesorio ${ }^{75}$.

En esta figura lo más importante es vincular a la parte contractual del contrato base, que no participó en el contrato derivado, con el subgarante, pues, en principio no tienen relación directa. Para ello hay que emplear la acción subrogatoria, pasando por el primer garante, dado que la acción directa, que sería más ventajosa, es excepcional y sólo puede emplearse cuando la ley la concede.

Es conveniente, entonces, que cuando no esté expresamente prevista en la ley, las partes prevean en el contrato base la posibilidad de subcontratación e incluyan expresamente la acción directa recíproca entre garantido y subgarante.

La promesa de hecho ajeno es otra modalidad contractual que puede emplearse en el ámbito de las garantías. Esta figura, regulada de manera incompleta en el artículo 1163 del Código civil y en los artículos 230 y 231 del Código de comercio, se da cuando, al momento de constituirse la obligación principal o con posterioridad, el deudor promete la garantía de un tercero. Generalmente el negocio de garantía precede al crédito o es contemporáneo de él, pero nada obsta que pueda ser posterior.

En la promesa de hecho ajeno el promitente se obliga a nombre propio por el hecho de otroy, en el contrato civil, puede garantizar o no su promesa. Si garantiza el cumplimiento y el tercero no quiere o no puede cumplir, debe la prestación; si sólo garantiza la aceptación por el tercero, debe daños y perjuicios. Si no garantiza, tiene sólo una obligación de medios, esto es, emplear la diligencia necesaria para que el tercero acepte.

Si el hecho ajeno prometido con garantía fuera una fianza, el deudor sólo puede garantizar la aceptación, pero no el cumplimiento, porque nadie puede ser fiador de sî mismo; en ese caso, si el tercero no acepta, debe los daños y perjuicios derivados de la falta de constitución de la fianza, además de lo debido con fuente en la obligación principal.

Por último, con relación a las modalidades contractuales de los negocios de garantía, nos interesa señalar la presencia permanentè de conexidad negocidl . La conexidad más evidente es la que aparece siempre entre el negocio principal y el accesorio de garantía, generalmente como una unión externa de contratos. Pero hay otras conexidades más interesantes y complicadas, como las que existen en los negocios sobre el rango en materia de hipoteca (art. 3135 del Código civil).

6. La causa-fin objetiva de los negocios de garantía tiene dos despliegues bien definidos: preventivo ${ }^{76}$ y resarcitorio. En primer lugar, ellos tienen por finalidad influir en la voluntad del deudor de modo tal que, por temor a la ejecución de la garantía, cumpla con su débito en tiempo y forma.

\footnotetext{
75 Un interesante caso de subfianza p.v. C.N.Com. Sala B, 15 feb.1995, autos "Gregoret, Rubén F. c/ Pescasur Sa.", LL. 1996-C, 381.

76 BARBERO, Doménico, op. cit., pág. 129, alude a este carácter diciendo que las garantias son "reforzadoras del cumplimiento".
} 
Subsidiariamente, para el caso de incumplimiento, la garantía es resarcitoria, porque otorga al acreedor la posibilidad de obtener la satisfacción de su crédito por una vía diferente (a veces también con una prestación diferente), porque "satisfacción del crédito" no significa siempre "cumplimiento del débito". Así, cuando ante el incumplimiento del deudor el acreedor debe recurrir a la garantía personal tomada, si bien obtiene el objeto debido, lo recibe de un tercero distinto al deudor y ello no es cumplimiento de la obligación ${ }^{77}$. Hay prestación sin cumplimiento, razón por la que procede la denominada "subrogación" del tercero en la posición del acreedor.

A veces la prestación del garante tampoco tiene identidad con la prestación debida, como ocurre en la ftanza de prestaciones de hacer o de entregar cuerpos ciertos, en las que el fiador debe entregar al acreedor prestaciones dinerarias (art. 1992 del Código civil). En estos casos varía tanto el sujeto como el objeto de la obligación incumplida.

7. Los negocios de garantía establecen relaciones jurídicas entre diferentes sujetos. En las garantías personales (y en las reales cuando el titular del bien sobre el que se constituye la garantía es un tercero), se relacionan acreedor y garante, garante y deudor, y acreedor y deudot. Por el contrario, en las garantías reales, cuando el deudor es titular del bien objeto de la garantía, sólo hay relación entre acreedor y deudor.

Para reconocer las diferentes relaciones jurídicas hay que diferenciar los negocios (el negocio garantizado y el de garantía) y admitir que no es un contrato plurilateral sino que se trata de dos o más negocios diferentes, aunque conexos ${ }^{78}$. En ocasiones estos negocios se otorgan contemporáneamente, formalizándose en el mismo instrumento, lo que hace todavía más dificultosa su diferenciación.

Entrando ahora a considerar los sujetos de esas relaciones jurídicas y comenzando por el acreedor hay que destacar que, si bien acreedor puede ser tanto una persona física como jurídica, es cada vez más frecuente que tengan este último carácter y sean, en la mayoría de los casos, entidades financieras. Por eso, como dijimos, prevalece la modalidad de contratación predispuesta y se observa un desigual poder de negociación.

En cuanto a los garantes, cuando son personas físicas generalmente habrá que tomar en cuenta su debilidad jurídica derivada del hecho, al que ya aludimos, de haber prestado la garantía en el marco de una relación familiar o amistosa con el deudor. Por eso, en el Proyecto de Unificación de la legislación civil y comercial de 1987 se intentó proteger indirectamente a las personas físicas disponiendo que sólo podrían otorgar fianzas simples, hasta sumas determinadas en el momento de la constitución, sin renunciar a causales de extinción ni a beneficios de excusión o de división. Por la misma razón, a veces la ley impide directamente a las personas físicas ser garantes, como ocurre con respecto al otorgamiento de la "garantía a primera demanda", que en numerosas legislaciones sólo

77 BARBERO, Doménico, op. cit., pág. 36.

${ }^{78}$ BIANCA, C. Massimo, Diritto..., op. cit., pág. 474, nota 28 hace referencia a la plurilateralidad. 
está autorizado para personas jurídicas ${ }^{79}$.

Las personas jurídicas de derecho público no pueden otorgar fianzas (art. 2011 inc. 2 del Código civil) y las sociedades civiles y comerciales se rigen por el contrato o estatuto social y, por tanto, sus representantes no pueden garantizar deudas ajenas si ese acto es notoriamente extraño al objeto social.

La relación acreedor-deudor-garante fue tradicionalmente un vínculo personal, que facilitó el conocimiento real de las personas y cierta consideración de las circunstancias de tiempo, lugar y personas. Hasta mediados de este siglo aseguraban negocios bien personalizados y vinculaban al acreedor con un garante seleccionado de manera particular, especialmente por el conocimiento que se tenía del mismo, por "estar abonado", en razón de "gozar en el lugar de un crédito indisputable de fortuna", como dice el artículo 1998 del Código civil.

En la actualidad, en cambio, la relación ha llegado a extremos inconcebibles en otras épocas. El deudor hipotecario, por ejemplo, que haya suscrito letras hipotecarias, en virtud de lo legislado en los artículos 35 y ss. de la ley № 24.441, puede llegar a tener, en la medida en que esos títulos circulen, una gran cantidad de acreedores a quienes no conocerá y que tampoco lo conocerán a él, por lo cual no tendrán la menor consideración con respecto a su situación particular. Este régimen riguroso, propio de las relaciones masificadas del mercado, pero altamente perjudicial para los sectores de medianos recursos por el riesgo de ejecución que implica, se introdujo en nuestro país alegando ser un instrumento apto para resolver los problemas habitacionales de la población y financiar la vivienda familiar en reemplazo de los créditos asistenciales del Banco Hipotecario Nacional.

A pesar de lo dicho, reconocemos que en estas relaciones que venimos analizando es importante brindar al acreedor una protección adecuada y equilibrada, precisamente para asegurar el cobro de su crédito. Los ordenamientos normativos así lo hacen tanto desde el Derecho privado como desde el penal.

En el Derecho privado se reconoce al acreedor el derecho a exigir garantías aun cuando no lo hubiera hecho al constituirse la obligación, si se dan algunos presupuestos (art. 2002 del Código civil), El acreedor deberá tener cuidado en esos casos porque la constitución de nuevas garantías puede llegar a configurar novación de la obligación anterior y causarle mayores perjuicios.

Además, el acreedor tiene derecho a exigir el mantenimiento o la renovación de las garantías cuando el fiador se torna insolvente (art. 2001 del Código civil) o el bien se deteriora (art. 3159, 3160 y 3.161 del Código civil).

\footnotetext{
${ }_{79}$ En Alemania así lo dispone la normativa BGH ZIP 1990, 1.186, cit. por MEDICUS, Dieter, op. cit., pág. 617. Entre nosotros igual criterio se incluyó en el art. 1479 del Proyecto de reformas al Código civil elaborado por la Comisión designada por decreto 468/92. En el Proyecto de Convención sobre las garantías independientes y las letras de crédito, citado en nota 12, las garantías autónomas pueden ser dadas por la banca, cualquier institución o persona.
} 
El principio general de la apariencia es también un instrumento útil empleado en este ámbito para proteger contra terceros al acreedor hipotecario de buena $\mathrm{fe}^{80}$.

Desde el Derecho penal resulta importante la tipificación de delitos en los que el valor protegido sean el crédito y la confianza, como la estafa y otras defraudaciones tipificadas en el Código penal argentino en los artículos 172, 173 inc. 11 y 175 inc. 3. Para que la protección penal sea eficaz, el legislador organiza un régimen suficientemente severo. En nuestro país, no puede decirse que la legislación penal de fondo no sea suficientemente protectoria. Sin embargo, en los hechos el sistema no se manifiesta con esas características, porque claudican los tribunales, cuando resuelven, por ejemplo, que no hay hecho típico penal (estafa, defraudación o insolvencia fraudulenta) si una persona enajena un inmueble el mismo día en que lo da en garantía para una tarjeta de crédito ${ }^{81}$.

Pese a todo, en el mundo de los negocios se desconfía de las garantías tradicionales acusándoselas de ser excesivamente retardatarias en el proceso de liquidación judicial y en el trámite del proceso penal. Esto condujo al legislador moderno a ofrecer alternativas más ágiles, aunque menos justas, tal como la autoliquidación prevista ahora para cualquier hipoteca siempre que se la pacte (art. 52 ley № 24.441).

Pero no sólo el acreedor necesita protección, sino también el garante frente a los abusos del acreedor. En ese sentido, hay en el Derecho privado numerosas normas que lo protegen del acreedor y de la connivencia de éste con el deudor principal (arts. 2015, 2018 y 2022 del Código civil).

En el Derecho francés hay una norma que merece especial mención, sobre todo por su aplicación a los contratos predispuestos. Se trata del artículo 1326 del Código civil, modificado por la ley № 80-525, del 12 de julio de 1980, que exige la mención de la suma o de la cantidad en letra y en números, escrita de puño y letra del deudor, cuando alguien se obliga a pagar una suma de dine ro o a entregar una cosa fungible. La jurisprudencia ha dicho que también en la fianza esa solemnidad es absoluta, de manera tal que su ausencia implica la nulidad del negocio ${ }^{82}$.

Entre nosotros, en materia de fianza, alguna jurisprudencia se ha preocupado en los últimos tiempos por proteger al fiador de la locación, disponiendo que la fianza se extingue si el locador ha dejado transcurrir largo tiempo antes de demandar al locatario el cumplimiento de sus obligaciones o la locación ha continuado en las condiciones previstas en el artículo 1622 del Código civil y luego el locatario deja de cumplir.

\footnotetext{
Bo "Se debe presumir la buena fe del aquí acreedor hipotecario en la constitución del acto (art. 2362 y 4008 Cod.civ.) al verse amparado por la apariencla juridica (registral y notarial), la onerosidad indiscutida del título y no siendo el supuesto vicio manifiesto, no cabe decretar la nulidad impetrada que le afecta en sus derechos"; C.N.Civ.Com Azul, 23 feb. 1994, autos "Santomauro Adelqui c/ Santomauro Donato", LLBA. 1994-15.

81 C.N.Crim.y Correc., Sala IV, 15 agosto 1991, autos "Bolognesi, Gustavo", LL.1992-B,326.

${ }^{82}$ Se trataba de un caso en el que una señora afianzó una obligación contraída por su esposo con una sociedad Locabail para la locación de un tractor. Aunque la fianza decía que se obligaba de manera solidaria e indivisible en los términos de la obligación de su esposo resultantes de contrato, como no cumplía con el mencionado artículo del Código fue declarada nula (Civ.1, 21 Juill.1987: Bull.civ.I,n.238), citado por SCHMIDT-SZALEWSKI, Joanna, op. cit., pág. 90.
} 
Pero ese sistema protectorio no se aplica a la "garantía a primera demanda" en la que el garante puede quedar a merced de un acreedor inescrupuloso, en cuyo caso sólo le quedará, en principio, en la vía civil, el recurso a la repetición por vía del juicio ordinario posterior al pago. Decimos en principio, porque en algunos casos se admite la excepción de abuso con prueba a cargo del garante, a pesar de que por su propia naturaleza significa renuncia a oponer excepciones y aunque en ella el pago sólo puede ser evitado si el garante prueba "de manera evidente, cierta e incontrovertible" que la deuda principal ha sido satisfecha. Por supuesto que, para ser admisible la exceptio doli, el abuso debe ser manifiesto. Esta excepción tiene, en la figura, tanta relevancia, que en el Proyecto de Convención sobre las garantías independientes y las letras de crédito de la Comisión de las Naciones Unidas para el Comercio Internaciona ${ }^{83}$, las dos únicas normas imperativas son las que refieren precisamente al abuso manifiesto y al fraude, todas las demás son supletorias.

En general, los tribunales son muy cautos con respecto a la exceptio doli. Sin embargo, en Italia la admiten cuando la mala fe es inmediatamente demostrable, llegando incluso a concederse la acción inhibitoria ${ }^{84}$ para impedir que se cause un daño inminente y grave al garante por el abuso del acreedor ${ }^{85}$.

Aún más, la propia banca italiana ha emitido normas para eliminar del uso algunas condiciones contractuales abusivas en las garantías a primera demanda, como las que reservan a la banca la facultad de modificar unilateralmente las normas que rigen la relación, y las que excluyen la obligación de la banca de dar noticia al garante acerca de la situación de las cuentas y el género de las relaciones habidas con el beneficiario del crédito garantido ${ }^{86}$.

El Derecho penal también trata de brindar ciertos instrumentos jurídicos para la defensa del deudor frente a los abusos del acreedor. El Código Penal argentino en su artículo 175 bis tipifica el delito de usura, diciendo que se configura cuando el acreedor, aprovechando la necesidad, ligereza o inexperiencia de su deudor, hiciera otorgar garantías de carácter extorsivo. Se reprime con pena de prisión de uno a tres años y multa. La prisión se eleva de tres a seis años si el autor fuera prestamista o comisionista usurario profesional o habitual.

Asimismo la ley № 24.441 intenta introducir mayor rigor en el régimen, disponiendo la reforma del artículo 173 del Código penal, relativo a la defraudación, al que agrega tres nuevos incisos, para reprimir al titular fiduciario, administrador de fondos comunes de inversión o dador de leasing que disponga, grave o perjudique los bienes en beneficio propio o de terceros; a quien autorizado para la liquidación extrajudicial de un inmueble

83 citado en nota 12 .

${ }^{84}$ Se denomina inhibitoria en el derecho italiano a la orden judicial impartida a una persona de abstenerse de un comportamiento ilicito. Tiene similitudes con la acción de amparo contra particulares reconocida en el art. 42 de nuestra Constitución nacional.

as BIANCA, C. Massimo, PATTI, Guido, PATTI, Salvador, Lessico...., op. cit., pág. 510.

$86 \mathrm{cfr}$. PONTIROLI, Luciano, op. cit., pag. 119. 
lo ejecuta en perjuicio del deudor, a sabiendas de que el mismo no se encuentra en mora, o maliciosamente omita cumplimentar los recaudos para la subasta; y al tenedor de letras hipotecarias que en perjuicio del deudor o de terceros omita consignar en el título los pagos recibidos.

En la relación acreedor-garante ambos tienen deberes específicos derivados de la buena fe. En cuanto al acreedor, la buena fe le impone informar correctamente al garante acerca de las condiciones de la deuda al momento de la constitución de la garantía y ser diligente en la tutela de su crédito frente al deudor; preocupándose por el mantenimiento actualizado de sus garantías complementarias, aun cuando teniendo un garante solvente, su interés en ellas fuera relativo (arts. 2015 y 2018 del Código civil).

El garante tiene, a su vez, la obligación de conservar el patrimonio que garantiza su solvencia, mantener informado al acreedor, y ser diligente en la verificación del cumplimiento del deudor, tratando de favorecer su cumplimiento e impedir su insolvencia ${ }^{87}$.

8. En lo que concierne a los efectos generales de las garantías hay que decir, en primer término, que ellas satisfacen al acreedor, quien, salvo pacto en contrario, tiene derecho a percibir del garante la totalidad de lo adeudado, con más los daños e intereses, o cobrarse sobre su patrimonio o sobre la cosa dada en garantía. Dejando de lado los perjuicios, está facultado a percibir por la obligación en sí misma las prestaciones adeudadas o menos, pero nunca más.

La inclusión de los daños y perjuicios en el monto que debe pagar el garante suele acrecentar considerablemente la carga que debe soportar, por lo cual se intenta de ordinario establecer convencionalmente un tope máximo hasta el cual éste responde, aunque en nuestro país no es frecuente que se logre incorporar pactos de esa naturaleza ${ }^{88}$.

La satisfacción del crédito por el garante es un acto jurídico unilateral, como el pago efectuado por el deudor, porque no puede ser rehusado por el acreedor en virtud del negocio preexistente, en nuestro caso el de garantía ${ }^{89}$.

El garante que paga tiene derecho a repetir del obligado todo o una parte de la prestación entregada, según el régimen de mancomunación que corresponda al caso, incluyendo los daños y perjuicios sufridos en su persona o en su patrimonio como consecuencia de dicho pago. Puede decirse que tiene la facultad de colocarse en el lugar del acreedor "subrogándose" en sus derechos, aunque técnicamente no se trate de una acción subrogatoria, sino de regreso contra el obligado principal, porque en la parte que

\footnotetext{
${ }^{87}$ V. C.N.Com., Sala C, 22 dic.1994, autos "Banco del Oeste S.A. en liq. c/ Calleja, Walter y otros", LL. 1996-A, 493, "No parece apropiado soslayar la responsabilidad de las fiadoras, por cuanto pese a que podría admitirse que el acreedor demoró la acción de cobro y el deudor fue declarado en quiebra, aquéllas omitieron desplegar una actividad que, al mismo tiempo de asegurar al acreedor el cobro del crédito, hubiere puesto a debido resguardo los propios bienes".

${ }^{88}$ ME.DICUS, Dieter, op. cit., pág. 613 dice que convencionalmente suele ponerse un monto máxímo hasta lo que responderá el fiador.

${ }^{8}$ BARBERO, Doménico, op. cit. pág. 43. En cambio cuando el tercero que satisface el crédito no tiene vínculo preexistente con el acreedor, puede éste rehusar el pago y si lo recibe celebra con él un contrato.
} 
corresponde a los daños y perjuicios que él sufrió no es una acción subrogatoria sino directa.

Hay que tener en cuenta que, cuando se ejecuta la garantía, se está ejecutando el negocio que es su fuente y no el negocio garantizado. Por ejemplo, en el juicio hipotecario se ejecuta el contrato de hipoteca y no el mutuo que con él puede haberse garantizado; lo que sucede es que, con el producido de esa ejecución, se satisface el otro crédito. Se trata de acciones diferentes que es indispensable separar, por un lado el acreedor tiene la acción hipotecaria y por otro la acción personal ${ }^{90}$ derivada del mutuo.

9. Por último, nos interesa reflexionar acerca del sistema de publicidad de las garantías. La publicidad permite establecer el orden de los privilegios y además facilita a los acreedores conocer los gravámenes que pesan sobre los bienes y decidir tomarlos, o no, en garantía.

Como es sabido las garantías reales, por su carácter de derechos reales, están sometidas a la publicidad registral, pero las garantías personales no tienen publicidad alguna, lo que facilita que garantes de mala fe procedan a su otorgamiento superando ampliamente su "posibilidad" patrimonial.

En la antigüedad el régimen de publicidad era posesorio, pues no se conocía la registración como sistema. La publicidad posesoria resul tó insuficiente respecto de las garantías reales, porque permitía modificar prontamente el patrimonio y mantener en secreto la composición de las fortunas. Con el fin de superar esos problemas y dar más agilidad y seguridad a la toma de crédito se crearon los registros.

Precisamente, los problemas que solucionó la publicidad registral de las garantías reales aparecen ahora respecto de las personales en aquellos casos en que un fiador, generalmente con escasa solvencia, que ha recibido una contraprestación por su garantía, afianza numerosas obligaciones de diferentes deudores frente a diversos acreedores que no pueden conocer por ningún medio el exceso de garantía con relación a la "posibilidad" patrimonial.

En Alemania está vehementemente discutida en este momento la problemática del otorgamiento de fianzas que supere ampliamente la "posibilidad" patrimonial del deudor, y su calificación como acto ilícito por contrario a las buenas costumbres ${ }^{91}$. Quizás esa solución pueda constituir un paliativo entre nosotros, pero no creemos que resuelva realmente y de fondo la cuestión, porque quienes incurren en esa conducta son de mala fe e insolventes. Aunque se trate de garantías que no comprometen bienes determinados, habrá que implementar algún sistema preventivo similar al registro.

so RIPERT, Georges, BOULANGER, Jean, op. cit, pág.60. Por eso consideramos erróneo lo expresado en la sentencia recaida en autos "Banco Tornquist S.A. c/ Farah Juan L. y otro", C.N.Civ., Sala B, 23 mayo 1994, LL.1994-D, 196, cuando dice: "Lo que en realidad se ejecuta no es la hipoteca sino el crédito que goza de tal garantía".

91 MEDICUS, Dieter, op, cit., pág. 612. 